Marquette University

e-Publications@Marquette

College of Education Faculty Research and

Publications

Education, College of

$1-1-2017$

\title{
Ethical and Political Implications of Reflective Practice among Preservice Teachers
}

Jeffrey LaBelle

Marquette University, jeffrey.labelle@marquette.edu

This is an Accepted Manuscript of an article published by Taylor \& Francis in Reflective Practice, Vol. 18, No. 5 (2017): 688-698, available online: https://www.tandfonline.com/doi/full/10.1080/ 14623943.2017.1307727. (c) 2017 Taylor \& Francis. Used with permission. 


\section{Ethical and political implications of reflective practice among preservice teachers}

Preservice teachers require more education than mere technical training to perform teaching tasks and conduct assessments (Zeichner, 2012). In order to empower new educators to be effective leaders in the $21^{\text {st }}$ century, preservice teacher programs need to develop the candidates' advanced ability in reflective practice. In a world of rapid technological, cultural, and political upheaval, educators must prepare themselves to analyze critically their role as agents of ethical and political transformation. To that end, I contend that teaching, of its very essence, is an ethical and political act. Indeed, Freire (2001, pp. 90-91) held no doubt that 'education...is a form of intervention in the world.' Ghaye (2008) considered the ethical implications of requiring students to engage in a new form of reflective practice in teaching contexts called participatory and appreciative action and reflection (PAAR). When viewed from a poststructuralist perspective, this requirement has an additional political dimension that challenges the premise that one can engineer dispositions without at least acknowledging such ethical and political matters.

This paper develops an argument that represents a theoretical position separate from the confines and constrictions of a positivistic research narrative. Such a research discourse is unduly limited to empirical data for purposes of compliance with state or federal teacher preparation standards. The richness, depth, and perspective of other kinds of discourse broaden the horizon of discussion about the value and purpose of reflective practice among preservice teachers to include more than the effective delivery of content and knowledge. In short, my aim is to widen the scope of discourse about preservice teacher dispositions too often treated as simply a form of policy enactment (Chapman, Forster, \& Buchanan, 2013). Here I unpack earlier statements about the naiveté of students who lack the necessary field experience to ground their idealistic, self- 
identified dispositions (LaBelle \& Belknap, 2016). Therein, we were alluding to professional practice within a neoliberal educational culture in which social justice risks becoming an exercise in audited compliance (Giroux, 2015). In addition, we dealt with a tension between our insistence on measuring dispositional growth and our assertion of the importance of care. In this present paper, I will explore any potential contradictions between the philosophical and methodological orientations of our previous research (LaBelle \& Belknap, 2016).

\section{Socially just practice vs. audited compliance}

Teaching is necessarily an ethical and political act. As referenced earlier, Freire (2001) views education as an intervention in the world. Furthermore, Freire envisions education as engagement 'in an effort to overcome debilitating dualisms because we are talking about the impossibility of separating the teaching of contents from ethical formation' (Freire, 2001, p 88). In short, teaching always entails an ethical posturing on the part of the educator, as well as expected ethical outcomes on the part of the learner. This ethical stance, in turn, leads to social and political transformation not only at the school site level, but in the surrounding community through civic engagement. Furthermore, by its very nature, socially just teaching advocates against mere audited compliance with core standards, standardized assessments, and universal learning outcomes (Giroux, 2015). Such an ethico-political posturing grounds itself in critical reflection. Because of this, preservice teachers need to develop skills and dispositions that position them as ethical and political change agents. One could then logically ask, 'What shape might such skill and dispositional development take?'

According to Carrington and Selva (2010), 'Reflection is the formation of a thought or idea as a consequence of meditation' (p. 45). Such a conceptualization of reflection supports not only a theoretical approach to education but also the 'application of theory that underlies a 
transformative approach to learning...' (p. 46). An essential element to critical reflection is experience: the real-life observation of and participation in teaching and learning processes in classroom contexts. This can involve everything from service learning to actual guided or supervised student teaching. "Nolan suggests that "skills for reflection can be taught and should play more of a role in pre-service teacher education courses" (p. 31)' (as cited by Carrington \& Selva, 2010, p. 48).

Experience, reflection, and critical analysis can lead preservice teachers to a deeper awareness of the ethical and political position that educators hold in society. Carrington and Selva (2010) make the case for the close link that '....reflection, particularly self-reflection' has '...with critical theory and thus transformational learning' (p. 45). This process from experience to reflection to critical analysis moves the preservice teachers to envision their role as educators in a new way, '... where teachers can imagine their role as contributing to a better education for all' (p. 54). In essence, a very intimate connection exists between these elements of preservice teacher training (experience, reflection, and critical analysis) which necessarily leads them to a newly developed ethical and political positionality for personal and social transformation.

As such, the development of skills and dispositions in preservice teachers is a triadic, interactional process involving theory, practice, and reflection (See Figure 1). Such interaction is complex because it takes place in social contexts and the three elements (theory, practice, and reflection) interdepend and mutually inform one another. Furthermore, this process needs to be seen in sociological and philosophical terms rather than as simply a cognitive or psychological process (Dyke, 2006). In fact, because such development is a process, it necessarily takes place across both time and space: hence, skill and dispositional development are never complete and never limited to any single context. Schon's (1983) seminal work on reflection-in-action and 
reflection-on-action accounts for such a process across time, but neglects to capture the necessary variation that takes place in situated learning environments. Hence, further conceptualizations such as reflection-in-context and reflection-on-context are appropriate expansions of both Dewey's (1933) and later Schon's (1983) notions of reflection. 'Dewey defined reflection as purposeful consideration of ideas in terms of the evidence presented and further implications of any conclusions drawn' (Daniel, Auhl, \& Hastings, 2013, p. 107). This conceptualization of reflection points to the need for people to interpret events intentionally to decide how to proceed with further action appropriate for that particular time and place. This type of '....reflection needs to be promoted as it represents an educational means of guiding people through modernity, a period of rapid change, of risk and of uncertainty' (Daniel, Auhl, \& Hastings, 2013, p. 105).

Daniel, Auhl, and Hastings (2013) studied a group of preservice teacher who interacted with their fellow candidates in the type of process just discussed. The purpose of this interactive process was the '...collaborative reflection and critique in a program that focuses on development of what some researchers refer to as core skills, or pedagogies of enactment, of teaching' (pp. 159-160). This approach represents one methodology for moving forward the process of ethical and political engagement of new educators. From their study of these preservice teachers, Daniel, Auhl, and Hastings (2013) concluded that the process exposed the preservice teachers to a new community of practice and helped them grow in their awareness of the value of critique as a way to integrate theory and practice. 'This growing awareness offers a challenge to the discourses of autonomy and niceness that currently restrict engagement in critical transformative dialogue within the teaching profession' (Daniel, Auhl, \& Hastings, 2013, p. 169). Indeed, the depth of preservice teachers' reflective practice needs to be increased and 
fostered to allow for multiple interpretive frameworks that challenge and strengthen their application of theories. As Dyke (2006) insisted, 'Reflection can be enhanced, nurtured more profound if it includes the engagement with different worldviews, perceptions and interpretations of experience' (p. 112). Engaging broader and more diverse worldviews, perceptions, and interpretations of experience not only leads to critical consciousness among preserve teachers, but also provides them with the theoretical grounding necessary for ethical and political action that leads to personal and social transformation.

\section{Dispositional growth and an ethic of caring}

This type of dispositional growth necessarily leads to the promotion of an ethic of caring on the part of educators (Noddings, 1984). Such a caring disposition is not limited to the individual care of the learner, but is open to the possibility of acting as a leader of community transformation beyond the school site. Indeed, as moral agents of social and political transformation, critical pedagogues are compelled to root out injustices within and without the classroom. This type of disposition might be termed commitment, that is, 'the more solidarity there is between teacher and student in the way this space is mutually used, the more possibilities for democratic learning will be opened up in the school' (Freire, p. 89, 2001).

In their study of teaching methodologies in teacher education programs, Chapman, Forster, and Buchanan (2013) noted that a mixed approach is highly indicated to promote moral development of preservice teachers. They cite examples of these methodologies including '...case-studies; a range of moral theories as ways to "see" moral problems; guided dialogue to communicate moral convictions; reflective journals for self-analysis and codes of ethics to provide normative foundations' (pp. 132-133). In order to interpret these sources of information 
from preservice teachers, they coded them according to five components of moral imagination (Joseph, 2003, p.16):

- Perception: The ability of people to become aware of others and their needs, desires, interests, wishes, hopes, and potentials.

- Rationality: Realistic understanding of situations calling for moral response and our knowledge of the particular issues and problems at stake. This is our ability to be flexible and not just apply a moral value or rule to every situation.

- Reflection: The continuing examination of beliefs and actions and consideration of how they affect other people and the questioning of the origins of our beliefs and values.

- Emotion: Feelings that permit sympathetic and empathic connection with and responsiveness to others. The catalyst for moral action is the capacity for feeling.

- Caring for self: Affirmation of individuals' need for their lives to have meaning and purpose. Awareness that as moral agents, individuals have needs that must be considered.

In addition, one must take care not to view such a process as a systematic or sequential process. Rather, I would suggest that each of these five facets of moral imagination intersect and interdepend (see Figure 2). Hence, teacher educators need to attend to all aspects of this framework throughout the process since they manifest themselves concurrently and affect one another in multiple ways. Chapman, Forster, and Buchanan (2013) concluded by discussing the importance of 'understanding moral imagination in teaching pre-service teacher ethics' and 'taking moral imagination seriously in teacher education' (p. 139). In addition, such understanding and serious consideration must lead to ethical and political engagement for personal and social transformation. In short, this process of self-awareness has the potential of 
going beyond professional mere moral development to become empowerment that has ethical and political ramifications.

\section{Authentic dispositional development of preservice teachers}

Although an authentic dispositional development might begin in the classroom, it ought to extend further to caring for the cultural, linguistic, racial, and socioeconomic contexts in which the learners are situated (Valenzuela, 1999). Otherwise, such dispositional development could run the risk of superficiality and might mirror Valenzuela's (1999) notion of minimalist or aesthetic caring. Teacher educators can enhanced such authenticity through multiple approaches to assist the preservice teachers in their dispositional development. For example, Etscheidt, Curran, and Sawyer (2011) present a three-level model of reflection: technical reflection, interactive journal writing and video-based analysis, and topical discussion during seminars. In our own previous work (LaBelle \& Belknap, 2016), based upon content analysis of preservice teachers' reflective journaling, we identified four different modalities or notions of fairness in preservice teacher perceptions: (1) inclusion of all socioeconomic classes and abilities; (2) culturally responsive teaching; (3) differentiation of instruction; and (4) fostering a safe learning environment. Indeed, Lee (2007) contends that teacher educators can use dialogue journals and response journals to encourage reflection among pre-service teachers.

Kuswandono (2014) underscores the affective nature of reflection that contains imbedded values. Often these same values need sorting, prioritizing, and reworking as part of a preservice teacher's professional growth and development. In some cases, teacher candidates must confront a cultural tension because of a clash between individualist and collectivist cultures. One method that preservice teachers can employ to explore this area is microteaching practice along with mentor and peer feedback. In any event, all methods of professional development for preservice 
teachers need to take into account not only the affective aspects, but also the social, cultural, and political engagement necessary for a more holistic and authentic moral development.

\section{Reflective practice: A method of dispositional development}

Such dispositional development demands a particular methodology of reflective practice enriched by the use of multiple resources and media. Husu, Toom, and Patrikainen (2008) concur that guided reflection and attention to reflective processes enhances the development of preservice teachers' professional knowledge. According to Larrivee (2008) the assessment of a teacher's level of reflection is essential to gauge how a prospective or practicing teacher is progressing in his or her development as a reflective practitioner. McDonald and Kahn (2014) stress the importance of course assignments designed to promote reflection processes and critical thinking of preservice teachers. McDonald and Kahn (2014) further conclude that the range of students' levels of reflectivity and critical examination; content knowledge, dispositions, and teaching skills; and epistemological beliefs might possibly mediate their level of reflectivity by either inhibiting reflective processes or supporting the reflective thinking flow. Thus, careful attention to reflective processes can foster a more critical consciousness among preservice teacher that in turn can empower them to advocate for personal and social transformation.

\section{Techniques}

Multiple techniques are available to promote and sustain reflective thinking processes among preservice teachers. One example is reflective writing and journaling (LaBelle \& Belknap, 2016). Since reflective writing is complex, Ryan (2011) proposes a social semiotic model for reflective writing to improve such skills among college students. In addition to this methodology, Harford and MacRuairc (2008) note the importance of peer critique and observations as a means of scaffolding reflective practice among student teachers. To accomplish this, preservice teacher 
programs could utilize peer-videoing, structured video analysis, and reflective dialogue to enhance the development of preservice teacher critical reflection (Harford \& MacRuairc, 2008). These techniques, and many others, not only help promote such critical analysis, but also a more complex understanding of literacy, teaching, and learning as well as issues of power and the unconscious in learning to teach (Heydon, \& Hibbert, 2010). Clearly, such probing into a deeper grasp of the subtleties of agency and power in literature would assist preservice teacher to comprehend the nature of their position as agents of social transformation.

Naidoo and Kirch's recent (2016) study presented a multifaceted approach to addressing the developmental needs of preservice teachers. They claimed that in order to 'change teachers' assumptions and practices, we must acknowledge that they are learners and they are re/creating new forms of practice that do not exist for them when learning is initiated' (Naidoo \& Kirch, 2016, p. 389). Such recreating of practice entails new methodologies for educating preservice teachers. To achieve this type of change in assumptions teacher educators need to 'provide tools, structures, and relationships necessary for learning new forms of practice' (Naidoo \& Kirch, 2016, p. 389).

Reflective writing, peer critique and observations, as well as peer-videoing, structured video analysis, and reflective dialogue are powerful tools that can help facilitate relationships of reciprocity and the critical epistemological curiosity (Freire, p. 67, 2001) necessary to construct the new forms of practice that Naidoo and Kirch recommend. Furthermore, Freire (2001) insisted, 'I do not see why I should omit or hide my political stance by proclaiming a neutral position that does not exist' (p. 68). In short, teaching based upon a critical consciousness is always political, never a non-neutral act. Once preservice teachers become critically aware of 
social injustices, they have the moral obligation to act consistently as ethical and political agents for personal and social transformation.

\section{Perceptions}

A much more elusive and challenging area of dispositional development is preservice teachers' perception. Hourani's (2013) qualitative exploratory case study analyzed the selfidentified perceptions of preservice student teachers via structured focus groups. Hourani (2013) concluded that there should be genuine and organic cultural base teaching to restructure and develop in teaching programs. This insight leads to the importance of self-reflection to help candidates critically analyze truth-telling on both theoretical and practical levels as well as to open them up to transformative dialogic practices. These interpersonal, dialogic practices might serve to challenge preservice teachers to more authentically assume their rightful ethical and political position in society. Keller and Keller's (2014) study united Adorno's self-reflection and self-awareness framework with Foucault's truth-telling and self-care concepts that can create and enhance social justice education (p. 360). Hence, education is more than just teaching: it allows people to reflect on what is taught that can effect change in the world. In short, Keller and Keller (2014) contend that reflection is something that cannot be taught. It is 'an inner activity that one must adopt for oneself' (p. 360). Central to effective reflection is the willingness to internally dialogue with oneself and the openness to question everything.

Furthermore, such self-reflection provides the preservice teachers an opportunity to consider what role agency plays. Felton and Koestler's (2015) study focused on the difference of teachercentered versus student-centered teaching in mathematics. They asserted that a teacher-centered approach creates a small area of flexibility that allows students to work on their own whereas a student-centered approach includes solving problems together with teachers and is much more 
interactive. With the increase of standardized testing and the tendency to teach to the test, implementing professionalism through critical reflection is more difficult (p. 273). Felton and Koestler (2015) concluded that, although the preservice teachers believed that reflection is important, most ( 9 of 16) believed that 'there is no need to change current mathematics teachings' (p. 267).This belief suggests the need for much deeper critical reflection in order to foster ethical and political connections on the part of the preservice teachers.

Choy, Wong, Goh, and Low (2014) researched preservice teacher perceptions to observe the 'expectations, fulfilment of expectations and overall experience during the three attachments [levels of practice teaching]' (p. 473). Choy, Wong, Goh, and Low (2014) concluded that the preservice teachers' first-hand experience gave them the real world experience needed for growth in confidence. Self-confidence and ego strength are essential for preservice teachers to assume their rightful role as agents of social and political transformation.

Bem (1972) established his Self-Perception Theory on how to ask questions and understand the mind. His theory analyzes self-perception based on the premise that more people than the individual can know that person's overt actions. Bem (1972) posits that self-perception differs from interpersonal perception in four different ways: insider vs. outsider, intimate vs. stranger, self vs. other, and actor vs. observer. Bem's (1972) theory of self-perception could broaden the range of analysis that preservice teachers employ in their reflective practice to think more critically about their specific classroom roles and how they impact the perceptive interpretation of their professional development as educators. This breadth of perception might well increase the preservice teacher's conceptualization of their ethical and political positionality.

Frye, Button, Kelly, and Button (2010) sought to raise awareness of 'how history, literacy and art were integrated in the college classroom and then taught in elementary classroom' (p. 7). 
They integrated Culturally Responsive Teaching (CRT) methods to help teacher candidates engage in cultural aspects in school (p. 6). Using pre- and post- testing to reflect on the experiences of the program, they examine if their CRT program changed the self-perceptions of teachers regarding the cultural aspects of teaching. Frye, Button, Kelly, and Button (2010) concluded, based on the self-perceptions of the teachers, that the preservice teachers' confidence increased through this cultural program. Once again, broadening the social consciousness of preservice teachers points to their ethical and political engagement inside and outside the classroom.

\section{Cognitive and affective development}

Reflective practice among preservice teachers entails both cognitive and affective development. Finlay (2008) viewed preservice teacher development and the use of reflective practice as a means of learning through and from experience; gaining new insights; examining assumptions, becoming self-aware and critically evaluating; and embracing an attitude of lifelong learning. All of these factors point to a type of professional development that goes beyond cognitive growth to include affective maturation. Woolhouse (2012) observed that preservice teachers often view themselves as unique from other teachers, as having distinct attributes and different motivations for pursuing their chosen career paths. This tendency might be associated with their reflective practice that leads them to become learners, develop their classroom practices, and feel more integrated into a specific community of practice. This integration into a community of practice can serve as both a cognitive and affective support system to enhance the ethical and political engagement of the preservice teachers.

Carrington and Selva (2010) provide a foundational definition of reflection: 'Reflection is the formation of a thought or idea as a consequence of meditation (p. 45). In addition, they contend 
that such reflection can be integrated via Butin's four lenses (2003): 1) technical, 2) cultural, 3) political, and 4) postmodern/poststructural. In using this framework, Carrington and Selva (2010) created a more critical, deeper analysis of the ways in which reflection can enhance the cognitive and affective development of the preservice teacher. These four lenses form a more expansive framework through which preservice teachers might interpret the ethical and political issues involved in teaching for social justice and social transformation.

Another area of importance in preservice teacher cognitive and affective development is selfefficacy. Often termed self-confidence, Bandura's (1993) conceptualization of perceived selfefficacy bears a closer look to enlighten teacher educators and inform preservice teacher program design. In his highly regard analysis of self-efficacy, Bandura (1993) reviews the various ways in which 'perceived self-efficacy contributes to cognitive development and functioning' (p. 117). Particularly pertinent to the matter at hand, is Bandura's insight that 'People's beliefs in their efficacy influence the types of anticipatory scenarios they construct rehearse' (p. 118). Hence, preservice teachers would do well to examine more reflectively their beliefs in themselves as effective educators even while anticipating their full placement into the classroom teaching for which they are rehearsing. Furthermore, Bandura's (1993) study of perceived efficacy makes it quite clear that this arena of concern impacts not only cognitive processes of the mind, but motivational, affective, and selection processes: such an assertion supports the claim of the great importance of reflective practice to enhance the holistic development of future educators which necessarily leads to ethical and political action.

\section{Conclusions and recommendations}

After carefully examining the ethical and political implications of an authentically reflective practice in preservice to teacher education, I propose the following benchmarks for 
program modification and improvement. These could serve as a teleological framework toward which all preservice teacher programs should strive.

- Ethical and political transformation, not technical training

- Empowerment and motivation, not compliance and standardization

- Creativity and resilience, not redundancy and replication

- Authentic caring and commitment, not superficial scaffolding and minimalization

In addition to establishing these benchmarks for program modification and improvement, teacher educators might interpret their preservice teacher experiences through Carrington and Selva's (2010) suggested four lenses: technical, cultural, political and postmodern/poststructural (Figure 3). These lenses could help teacher educators better interpret the developmental processes of preservice teachers to more effectively inform their program modification and improvement. As Naidoo and Kirch (2016) pointed out,

'At a minimum, these learners require mediation that frames the identification of problems, the development of multiple perspectives, and the negotiation of solutions (Loughran, 2002) and prompts the full range of reflection actions including retrospection (thinking back), selfevaluation (analysis), and re-orientation (future-oriented planning; Quinn, 1988/2000),' (p. 389).

I recommend that teacher educators implement these four interpretive lenses as a frame to assist preservice teachers to reflect upon the ethical and political implications of their teaching. As Loughran (2002) indicated, such reflection can lead to the negotiation of solutions. Such solutions, I would add, are not limited to classroom teaching, but extend to the ethical and political transformation of society at large. 
Unfortunately, multiple factors exist that might inhibit the implementation of such a process of reflective practice. Some of the obstacles in teacher education programs are due to the constraints of state licensure requirements or graduation accreditation standards. For example, licensure candidates must pass content knowledge exams such as the Praxis Series as well as meet or exceed Teacher Performance Assessment (edTPA) benchmarks to qualify for state teacher certification. These assessments neither measure nor emphasize the ethical or political implications of reflective practice as essential learning outcomes of preservice teacher programs. Furthermore, candidates often are extremely preoccupied and constrained with time limitations in preparation for passage of both of these mandatory requirements. In addition, the preservice teacher must maintain certain minimum grade point averages in order to qualify for state licensure, as well as financial scholarship requirements. All of these factors combined severely limit the available time, appropriate ethos, and focused attention necessary to promote effective reflective practice among preservice teachers. In the final analysis, each preservice teacher program will need to take into account these factors in order to implement more effectively the reflective process recommended here. 


\section{References}

Bandura, A. (1993). Perceived self-efficacy in cognitive development and functioning. Educational Psychologist, 28(2), 117-148.

Bem, D. J. (1972). Self-perception theory. Advance in Experimental Social Psychology, 6.

Carrington, S., \& Selva, G. (2010). Critical social theory and transformative learning: Evidence in pre-service teachers' service-learning reflection logs. Higher Education Research \& Development, 29(1), 45-57.

Chapman, A., Forster, D., \& Buchanan, R. (2013). The moral imagination in pre-service teachers' ethical reasoning. Australian Journal of Teacher Education, 38(5), 131-143.

Choy, D., Wong, A. F. L., Goh, K. C., \& Low, E. L. (2014). Practicum experience: Pre-service teachers' self-perception of their professional growth. Innovations in Education and Teaching International, 51(5), 472-482.

Daniel, G. R., Auhl, G., \& Hastings, W. (2013). Collaborative feedback and reflection for professional growth: Preparing first-year pre-service teachers for participation in the community of practice. Asia-Pacific Journal of Teacher Education, 41(2), 159-172.

Dewey, J. (1933). How we think: A restatement of the relation of reflective thinking to the educative process. Lexington, MA: Heath \& Co.

Dyke, M. (2006). The role of the 'Other' in reflection, knowledge formation and action in a late modernity. International Journal of Lifelong Education, 25(2), 105-123.

Etscheidt, S., Curran, C. M., \& Sawyer, C. M. (2011). Promoting reflection in teacher preparation programs: A multilevel model. Teacher Education and Special Education, $20(10), 1-20$. 
Felton, M. D., \& Koestler, C. (2015). "Math is all around us and ... we can use it to help us": Teacher agency in mathematics education through critical reflection. The New Educator, 11(4), 260-276.

Finlay, L. (2008). Reflecting on 'reflective practice,' Practice-based Professional Learning Centre, January. Retrieved from www.open.ac.uk/pbpl

Freire, P. (2001). Pedagogy of freedom: Ethics, democracy, and civic courage. Lanham, MD: Rowman \& Littlefield Publishers.

Frye, B., Button, L., Kelly, C., \& Button, G. (2010). Preservice teachers' self-perceptions and attitudes toward culturally responsive teaching. Journal of Praxis in Multicultural Education, 5(1), 6-22.

Ghaye, T. et al. (2008). Participatory and appreciative action and reflection (PAAR) democratizing reflective practices. Reflective Practice, 9(4), 361-397.

Giroux, H. A. (2015). Education and the crisis of public values: Challenging the assault on teachers, students, and public education ( $2^{\text {nd }}$ ed.). New York, NY: Peter Lang Publishing, Inc.

Harford, J., \& MacRuairc, G. (2008). Engaging student teachers in meaningful reflective practice. Teaching and Teacher Education, 24, 1884-1892.

Heydon, R., \& Hibbert, K. (2010). 'Relocating the Personal' to engender critically reflective practice in pre-service literacy teachers. Teaching and Teacher Education, 26, 796-804.

Holloway, S. M., \& Gouthro, P. A. (2011). Teaching resistant novice educators to be critically reflective. Discourse: Studies in the Cultural Politics of Education, 32(1), 29-41.

Hourani, R. B. (2013). Pre-service teachers' reflection: Perception, preparedness and challenges. Reflective Practice, 14(1), 12-30. 
Husu, J., Toom, A., \& Patrikainen, S. (2008). Guided reflection as a means to demonstrate and develop student teachers' reflective competencies. Reflective Practice, 9(1), 37-51.

Joseph, P. (2003). Teaching about the moral classroom: Infusing the moral imagination into teacher education, Asia-Pacific Journal of Teacher Education, 31(1), 7-20.

Keller, D. B., \& Keller, J. G. (2014). Politics and transformation: Critical approaches toward political aspects of education. Policy Future in Education, 12(3), 359-369.

Kuswandono, P. (2014). University mentors' views on reflective practice in microteaching: Building trust and genuine feedback. Reflective Practice, 15(6), 701-717.

LaBelle, J., \& Belknap, G. (2016). Reflective journaling: Fostering dispositional development in preservice teachers. Reflective Practice, 17(2), 125-142.

Larrivee, B. (2008). Development of a tool to assess teachers' level of reflective practice. Reflective Practice, 9(3), 341-360.

Lee, I. (2007). Preparing pre-service English teachers for reflective practice. English Language Teaching Journal, 61(4), 321-329.

Loughran, J. (2002). Effective reflective practice: In search of meaning in learning about teaching. Journal of Teacher Education, 53, 33-43.

McDonald, D., \& Kahn, M. (2014). So, you think you can teach? Reflection processes that support pre-service teachers' readiness for field experiences. International Journal for the Scholarship of Teaching and Learning, 8(2), 1-34.

Naidoo, K., \& Kirch, S. A. (2016). Candidates use a new teacher development process, Transformative Reflection, to identify and address teaching and learning problems in their work with children. Journal of Teacher Education, 67(5), 379-391. 
Noddings, N. (1984). Caring: A feminine approach to ethics \& moral education. Berkeley, CA: University of California Press.

Quinn, F. M. (2000) Reflection and reflective practice. In C. Davies, L. Finlay, \& A. Bullman (Eds.), Changing practice in health and social care. London, England: SAGE. (Original work published 1988).

Ryan, M. (2011). Improving reflective writing in higher education: A social semiotic perspective. Teaching in Higher Education, 16(1), 99-111.

Schön, D. (1983). The reflective practitioner: How professionals think in action. New York, NY: Basic Books.

Valenzuela, A. (1999). Subtractive schooling: U.S.-Mexican youth and the politics of caring. Albany, NY: State University of New York Press.

Woolhouse, C. (2012). Reflective practice and identity construction: The particularities of the experiences of teachers specializing in dyslexia. Reflective Practice, 13(6), 747-760.

Zeichner, K. (2012). The turn once again toward practice-based teacher education. Journal of Teacher Education, 63(5), 376-382. 
Figure 1. Interdependent Pedagogical Cycle

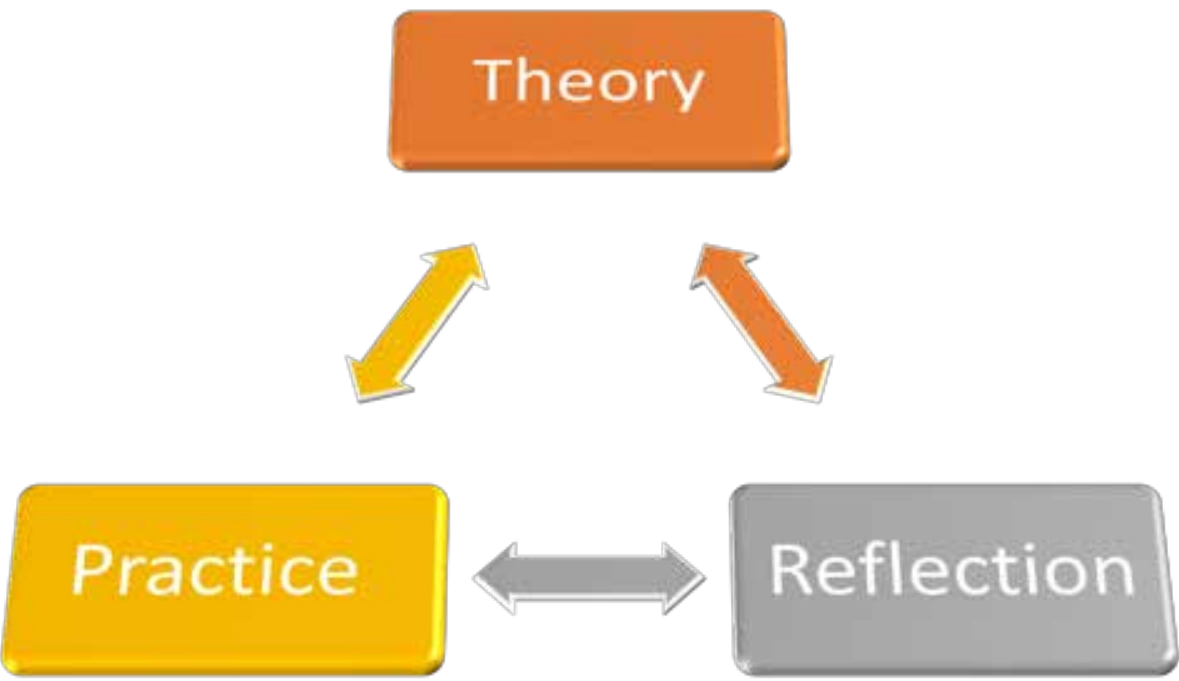




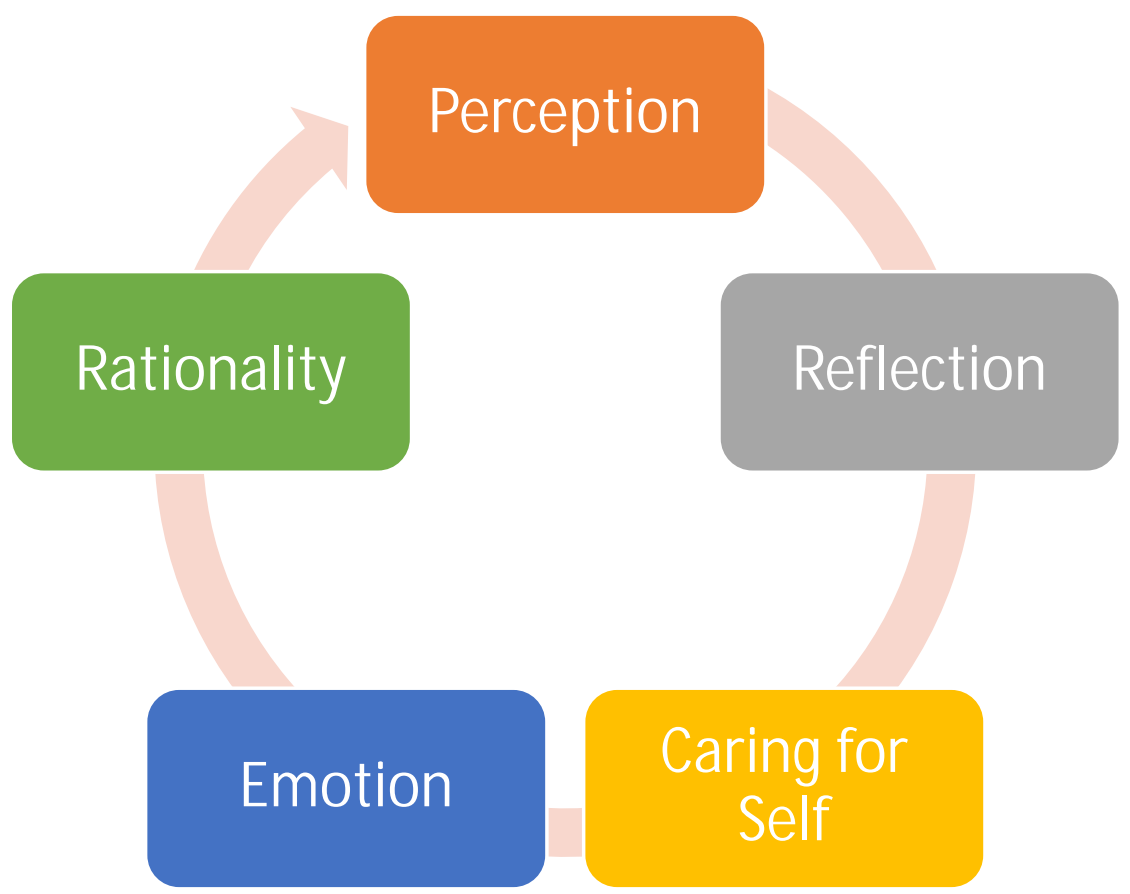

Figure 2. Interdependent Factors of Moral Imagination 


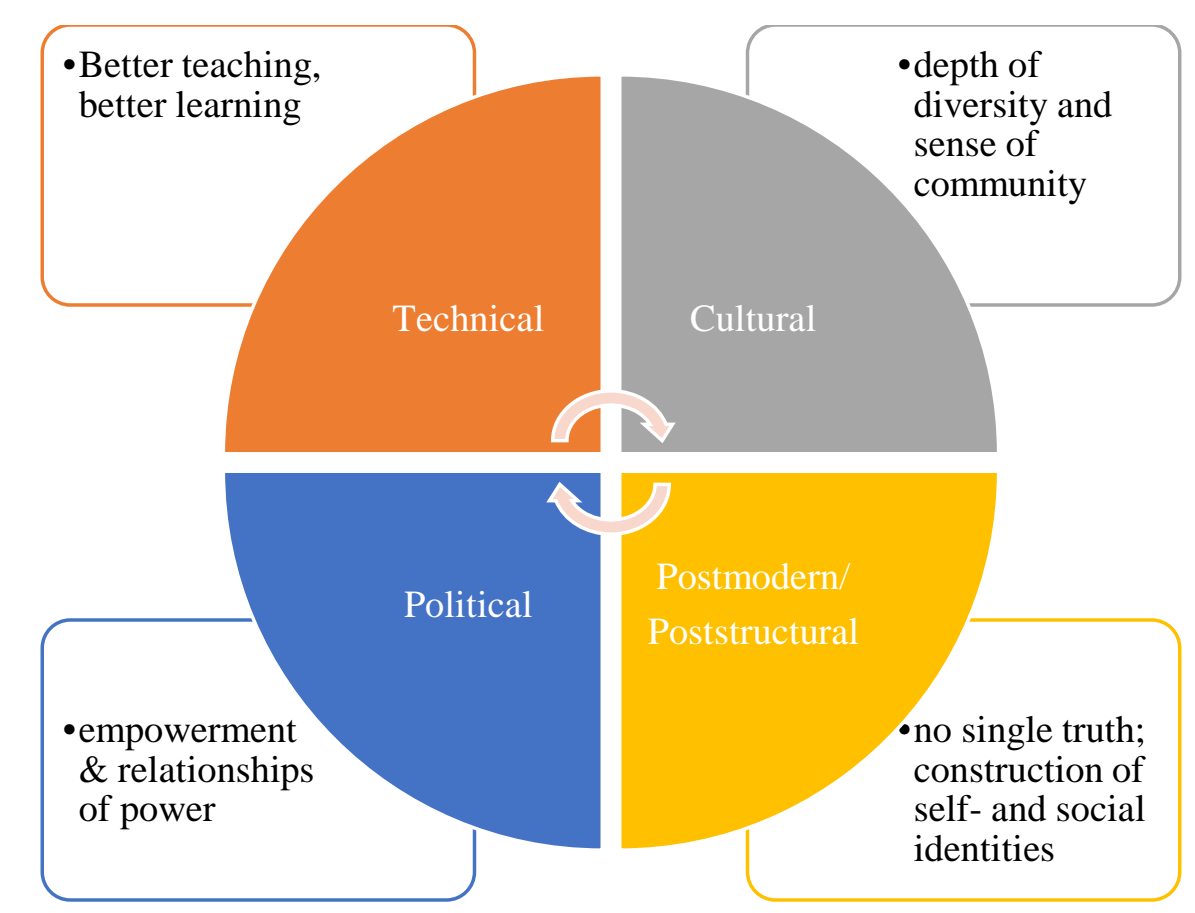

Figure 3. Interpretive Lenses for Preservice Teachers 